\title{
A COMPARATIVE STUDY OF CONDYLAR GUIDANCE SETTING OBTAINED FROM INTEROCCLUSAL RECORDS AND PANORAMIC RADIOGRAPHS IN BOTH DENTULOUS AND EDENTULOUS SUBJECTS
}

\author{
Sharad Acharya ${ }^{1}$, Avni Pandey ${ }^{2}$, Sumit Sethi ${ }^{3}$, Manoj Kumar Meena ${ }^{4}$ \\ ${ }^{1}$ Sr. Lecturer, Department of Prosthodontics, Daswani Dental College \& Research Centre, Rajasthan, India \\ ${ }^{2}$ Sr. Lecturer, Department of Prosthodontics, Daswani Dental College \& Research Centre, Rajasthan, India \\ ${ }^{3}$ Reader, Department of Prosthodontics, Daswani Dental College \& Research Centre, Rajasthan, India \\ ${ }^{4}$ Sr. Lecturer, Department of Prosthodontics, Daswani Dental College \& Research Centre, Rajasthan, India
}

\begin{abstract}
To compare the condylar guidance values obtained from interocclusal records and the panoramic radiographs in both dentulous and edentulous subjects. Materials \& Methods : 20 dentulous and 20 edentulous subjects having specific criteria were selected for the cross-sectional descriptive in-vivo study. In the first method, the sagittal condylar guidance values for both the groups were recorded after obtaining protrusive records using HANAU articulator model Wide-Vue, U.S.A. In the second method panoramic radiographs were made of all the edentulous and dentulous subjects in the natural head position and tracings were done of the outline of glenoid fossa and the articular eminence. The angles formed by the lines drawn were measured and the values obtained were compared with those from the inter-occlusal record method. The condylar guidance readings of both dentulous and edentulous subjects obtained from the interocclusal records and those by tracing panoramic radiographic images were compared by Mann Whitney U test and Karl Pearson's coefficient of correlation test. Results: The condylar guidance values obtained from the interocclusal records were less when compared to the values obtained from tracing the panoramic radiographs. Significant correlation $(r=0.9)$ between the condylar guidance values obtained for left and right sides in interocclusal record group and a moderate correlation ( $\mathrm{r}=0.65)$ between the condylar guidance values obtained for left and right sides from panoramic radiographs. Conclusion: The results from this study showed that measurement of condylar inclination angles using panoramic radiographs gave higher values, as compared to the inter-occlusal record method. Also, panoramic radiographic method revealed less difference between the condylar guidance values obtained for left and right sides as compared to the articulator method. Although, significant amount of correlation was found between the two methods, variations due to different operators and better radiographic techniques should be further investigated.
\end{abstract}

Key words: Condylar Guidance, Protrusive Interocclusal Records, Articular Eminence, Panoramic Radiographs.

\section{INTRODUCTION}

Successful treatment of edentulous patients is based on long term reestablishment of function and on the preservation of the alveolar bone. Providing harmony between the occlusal surfaces of the artificial teeth and the condylar paths plays a significant role in both function and preservation. ${ }^{1}$ In clinical practice, the methods most often used to determine the inclination of the condylar path are based on the Christensen's phenomenon which consists in employing intraoral wax records and sharry31@rediffmail.com Received: $25^{\text {th }}$ February 2015 Accepted:30 July 2015 Online: $10^{\text {th }}$ September 2015 different techniques of setting condylar inclination values using different interocclusal records to program the articulator. Since the images on the panoramic radiograph provide sagittal representations of the skeletal structures, the outline of the articular eminence can be used as an aid in setting the condylar guidance inclination of a semi-adjustable articulator. $^{2}$

Hence, this study was proposed to determine the correlation between the anatomic shape of the articular eminence and the corresponding panoramic radiographic images in dentulous and edentulous human subjects. 


\section{MATERIALS AND METHODS:}

This cross-sectional descriptive in-vivo study was conducted including 20 dentulous and 20 edentulous subjects having specific criteria. The ethical clearance was obtained from the Ethical committee of the institution before starting the study. 20 dentulous subjects with nearly ideal occlusion aged between 18 $30 \mathrm{yrs}$ and 20 completely edentulous subjects aged between 45-75 yrs were selected for the study.

\section{Making of interocclusal records for edentulous subjects:}

Primary impressions of maxillary and mandibular arches were made using impression compound (DPI Pinnacle, INDIA) which were poured with dental plaster to obtain the primary casts. Border moulding was done and final impressions were made using zinc oxide eugenol impression paste (DPI Impression Paste, INDIA). Then tentative jaw relation and facebow transfer (Spring-bow; Teledyne, U.S.A) was done and maxillary casts were mounted on a semi-adjustable articulator (HANAU articulator model Wide-Vue, U.S.A). Mandibular casts were mounted with centric relation record made using bite registration paste (Regisil Rigid, Super Fast Set, Dentsply, U.S.A). Extra oral gothic arch tracers ((Hanau Hight Tracers CAT no.28-0 Teledyne, U.S.A) were attached to the occlusal rims and the subject was then asked to perform the eccentric movements i.e. right lateral, left lateral and protrusive movements (Figure 1) to obtain the arrow point tracing over the smoked extra oral plate.
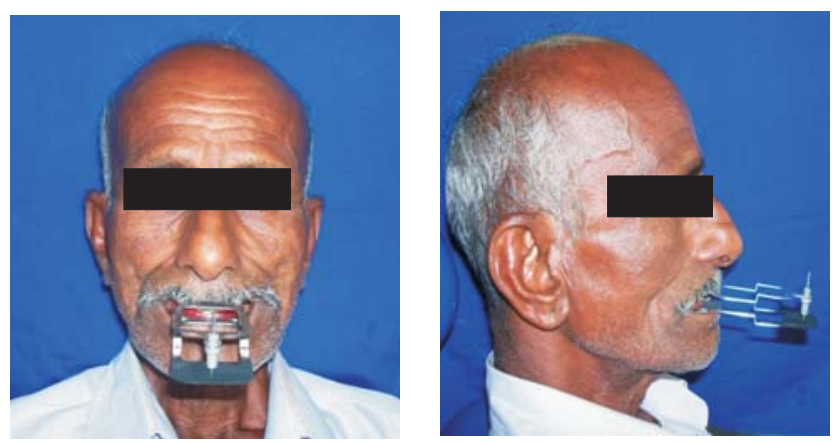

Figure 1: Showing the Extra-oral tracer assembly in subject's mouth

The protrusive inter-occlusal record was made by asking the subject to protrude the mandible forward by $6 \mathrm{~mm}$ (Figure 2). The records were transferred to the articulator and condylar guidance values were obtained when the rims were fully seated.

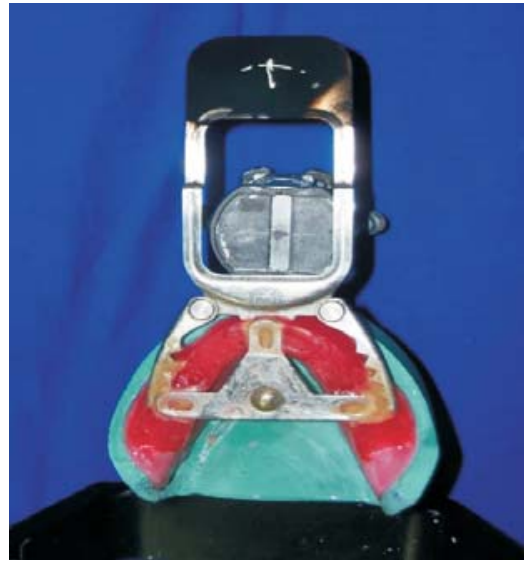

Figure 2: Showing the arrow point tracing given by the subject

Making of interocclusal records for dentulous subjects:

For dentulous subjects an anterior programming device or jig $2.5 \mathrm{~cm}$ in length bent into a 'J' shape was made to establish a definite vertical stop and allows muscle function to be reprogrammed to eliminate the adaptive arc of closure. To make the record, the interocclusal recording material was injected into the subject's mouth and was asked to close gently into the indentations of the jig 4-6 mm forward in a straight line (Figure 3). The protrusive records were transferred to the articulator and the correct value of condylar inclination was noted when the records were seated correctly on the casts (Figure 4).

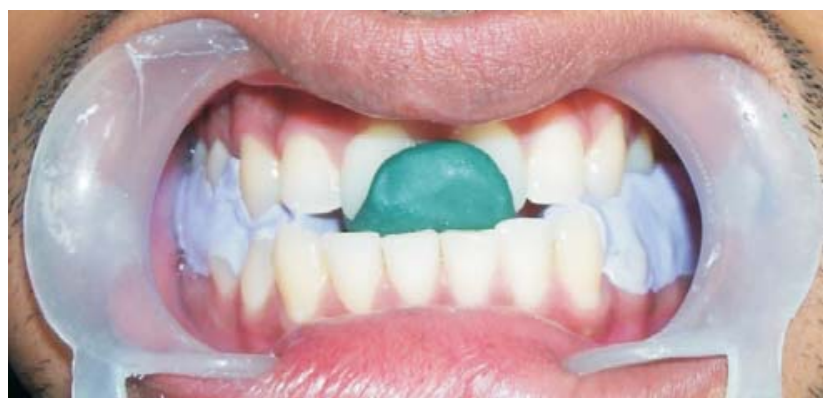

Figure 3: Showing the protrusive record made along with the jig
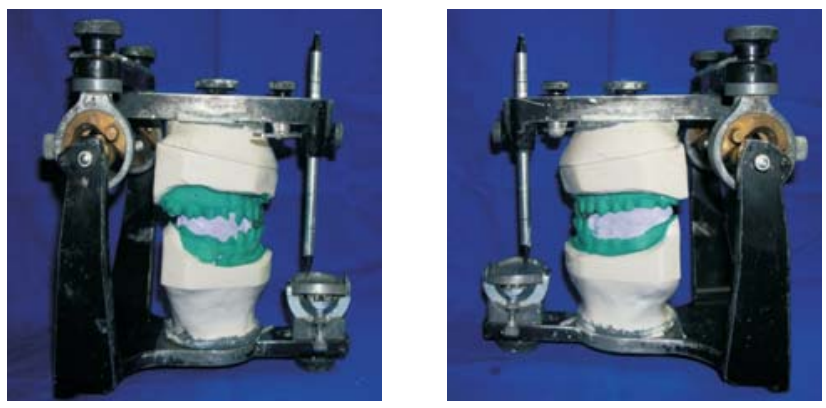

Figure 4: Showing the setting of condylar guidance values using the protrusive record 
Obtaining panoramic radiographs of the subjects:

For making the panoramic radiographs, each subject was asked to stand straight in panoramic radiographic unit (Orthoralix 9200; Gendex Dental Systems, Milan, ITALY) with head properly stabilized and patient was strictly instructed not to move during the radiographic exposure. To standardize the placement of the landmarks in a panoramic image, the subjects were oriented to the Frankfort horizontal plane and the upper border of the radiograph parallel to the floor (Figure 5).The Frankfort horizontal plane was represented by a line passing through the points, porion and orbitale. To locate these two points on the radiographs, gutta percha points $(1 \mathrm{~mm})$ were used as the radiopaque markers. All the radiographs were made with normal exposure $(74 \mathrm{kV}, 10 \mathrm{~mA}, 12 \mathrm{sec})$.

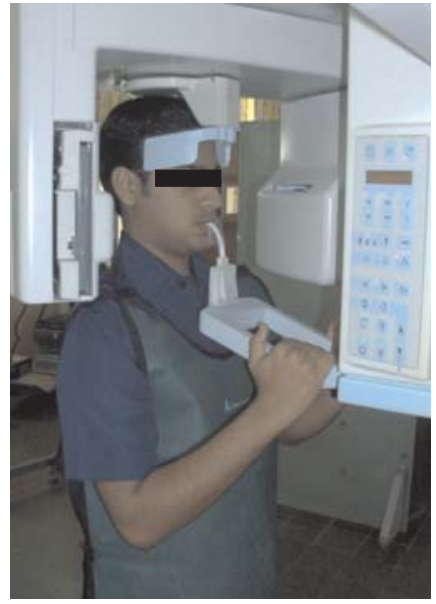

Figure 5: Showing the subject oriented in the radiographic unit with Frankfort horizontal plane parallel to the floor

Tracing of panoramic radiographs and obtaining the condylar inclination values:

Tracings were made of the radiographic images of inner outline of glenoid fossa and outer incline of articular eminence on an acetate matte tracing paper (0.003 inches, $8 \times 10$ inches) (Figure 6). Two radiopaque

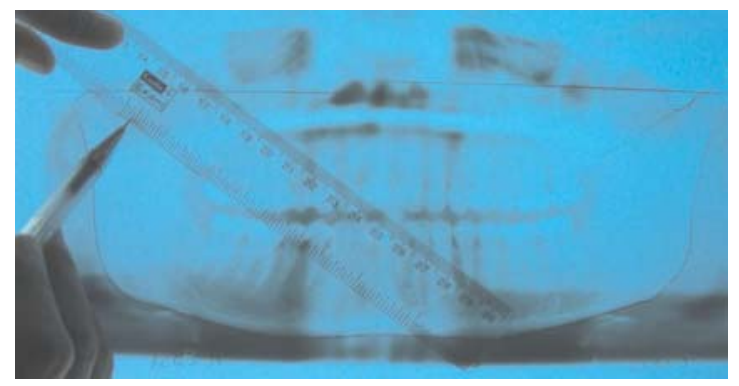

Figure 6: Showing the procedure of tracing done on acetate matte tracing paper markers corresponding to the points representing the Frankfort horizontal plane on the soft tissues (lowest point on the inferior orbital margin and the uppermost point on the superior margin of the temporomandibular fossa) were apparent on the panoramic radiographs. The ' $S$ ' shaped outline formed by joining the glenoid fossa and articular eminence was traced. The horizontal reference line representing the Frankfort horizontal plane formed by joining the two radiopaque markers was also traced. Since the 'S' shaped curve obtained from the tracing is a curved path, a tangent was drawn along the ' $\mathrm{S}$ ' shaped curve joining two points.

\section{Statistical analysis followed:}

The condylar guidance readings for both dentulous and edentulous subjects obtained from interocclusal records and those from tracing panoramic radiographic images were compared by Mann Whitney U test and Karl Pearson's coefficient of correlation test. The level of significance was set at probability level of $\mathrm{P}<0.005$.

\section{RESULTS}

The condylar guidance values obtained from interocclusal records were less as compared to the values obtained from tracing of panoramic radiographs. The results from Table 1 , Graph $1 \& 2$ showed that, the mean difference of condylar guidance values for dentulous subjects on left side between interocclusal record group and panaromic radiographic group was 0.2 , which was not statistically significant $(p=0.7)$. The results also showed that the mean difference of condylar guidance values for dentulous subjects on right side between the two groups was 0.1 which was not statistically significant $(p=0.1)$. Again from the above results, it can be inferred that there is a significant correlation between interocclusal record group and panoramic radiograph group on left $(\mathrm{r}=0.55)$ and right $(\mathrm{r}=0.57)$ sides for dentulous subjects. The results from Table 2 , Graph $3 \& 4$ showed that there is a significant correlation for both left $(\mathrm{r}=0.72)$ and right $(\mathrm{r}=0.57)$ sides for edentulous subjects. Also, the mean difference for the left side was found to be -2.75 which was statistically significant. The results from the Table 3, showed that the mean difference of condylar guidance values for dentulous patients between left and right sides was 0.5 for interocclusal record group which was not statistically significant $(\mathrm{p}=0.15)$. The results from the Table 4 
Table 1: Showing the mean difference and correlation coefficient comparing interocclusal record group and panoramic radiograph group for both right and left sides among dentulous subjects using Mann Whitney U test and Karl Pearson's coefficient of correlation test.

\begin{tabular}{|c|c|c|c|c|c|c|}
\hline $\begin{array}{c}\text { Dentulous } \\
\text { subjects }\end{array}$ & $\begin{array}{c}\text { Inter occlusal } \\
\text { record }\end{array}$ & $\begin{array}{c}\text { Panoramic } \\
\text { radiograph }\end{array}$ & $\begin{array}{c}\text { Mean } \\
\text { Difference }\end{array}$ & $\mathbf{p ~ V a l u e}$ & $\begin{array}{c}\text { Coefficient of } \\
\text { correlation }\end{array}$ & Significance \\
\hline Left & 34.25 & 34.05 & 0.20 & $0.7 \mathrm{NS}$ & 0.55 & $0.01 \mathrm{~S}$ \\
\hline Right & 33.75 & 35.8 & -2.05 & $0.1 \mathrm{NS}$ & 0.57 & $0.008 \mathrm{~S}$ \\
\hline
\end{tabular}

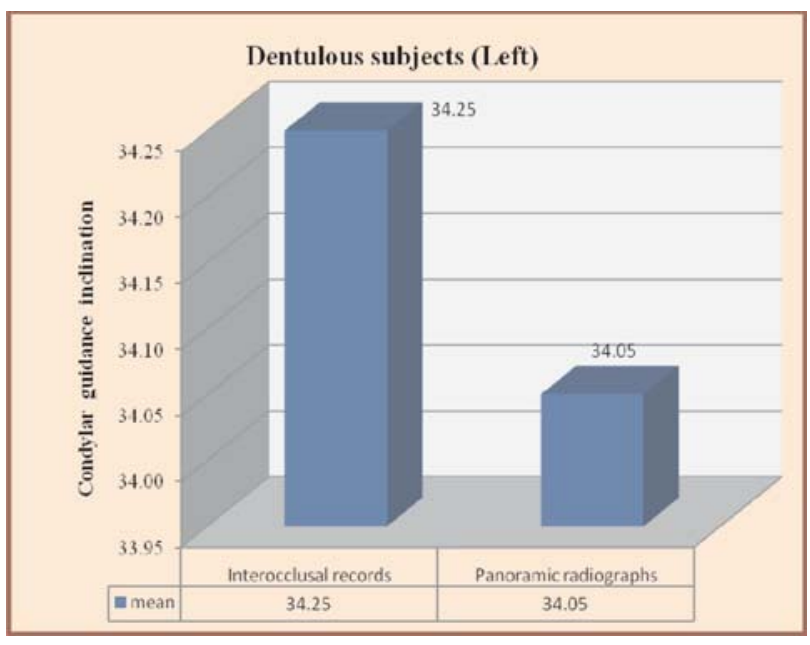

Graph 1: Showing the mean difference and comparison between the two methods in dentulous subjects for left side.

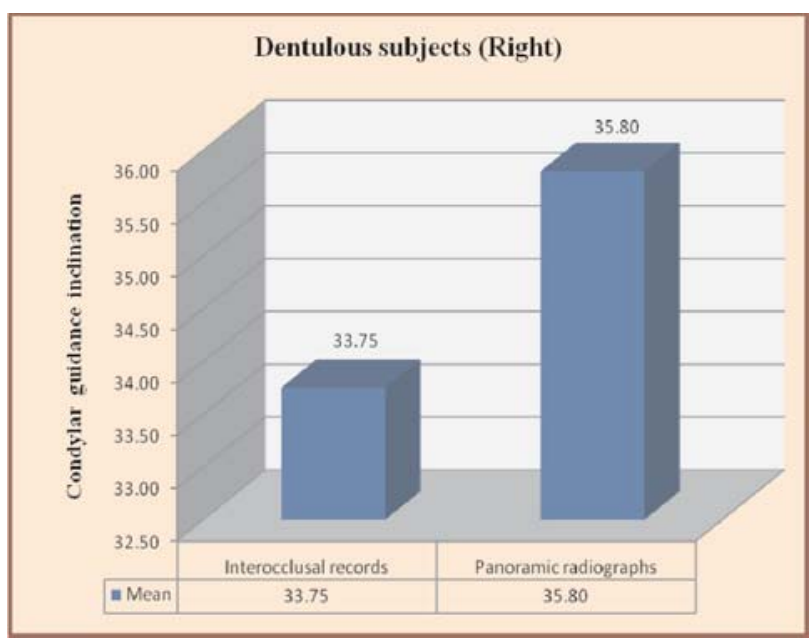

Graph 2: Showing the mean difference and comparison between the two methods in dentulous subjects for right side.

Table 2: Showing the mean difference and correlation coefficient comparing interocclusal record group and panoramic radiograph group for both right and left sides among edentulous subjects using Mann Whitney U test and Karl Pearson's coefficient of correlation test.

\begin{tabular}{|c|c|c|c|c|c|c|}
\hline $\begin{array}{c}\text { Edentulous } \\
\text { subjects }\end{array}$ & $\begin{array}{c}\text { Inter occlusal } \\
\text { record }\end{array}$ & $\begin{array}{c}\text { Panoramic } \\
\text { radiograph }\end{array}$ & $\begin{array}{c}\text { Mean } \\
\text { Difference }\end{array}$ & p Value & $\begin{array}{c}\text { Coefficient } \\
\text { of correlation }\end{array}$ & Significance \\
\hline Left & $26.75^{\circ}$ & $29.50^{\circ}$ & -2.75 & $0.09 \mathrm{NS}$ & 0.72 & $<0.001 \mathrm{HS}$ \\
\hline Right & $26.50^{\circ}$ & $30.35^{\circ}$ & -3.85 & $0.02 \mathrm{~S}$ & 0.57 & $0.008 \mathrm{~S}$ \\
\hline
\end{tabular}

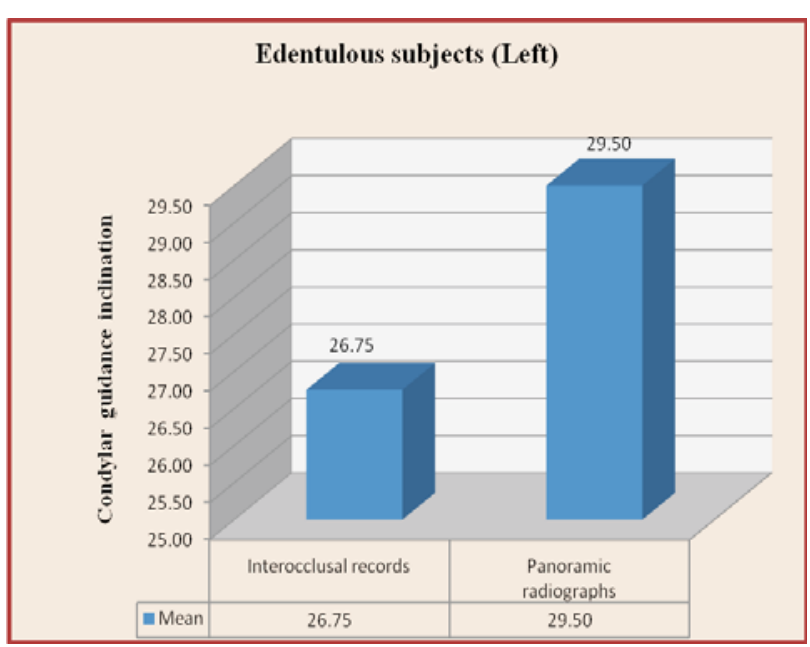

Graph 3: Showing the mean difference and comparison between the two methods in edentulous subjects for left side.

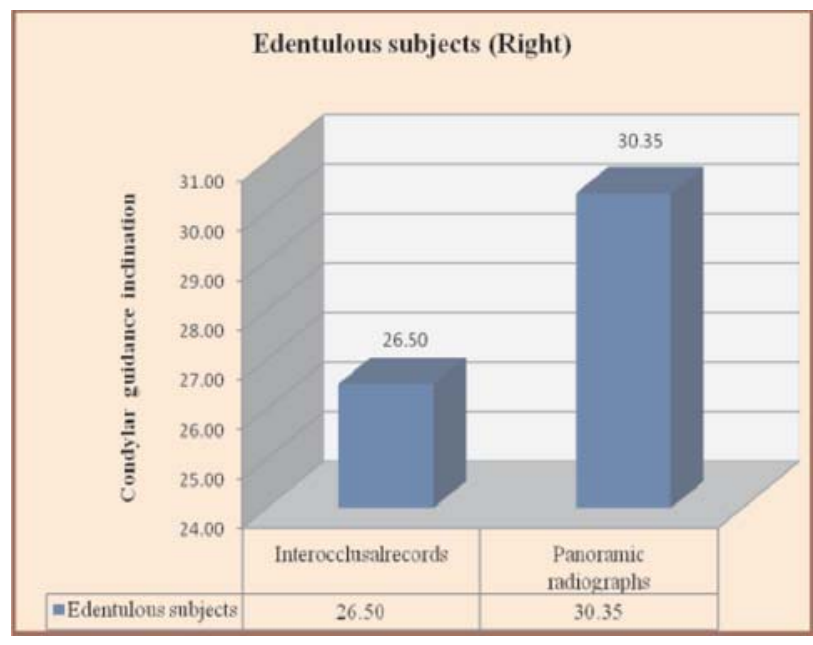

Graph 4: Showing the mean difference and comparison between the two methods in edentulous subjects for right side. 
Table 3: showing the mean difference and correlation coefficient comparing both leftand right sides of interocclusal record group and panoramic radiograph group among edentulous subjects using Wilcoxon signed rank test and Karl Pearson's coefficient of correlation test.

\begin{tabular}{|c|c|c|c|c|c|}
\hline Dentulous subjects & Sides & Mean & Mean difference & $\begin{array}{c}\text { P Value, } \\
\text { Significance }\end{array}$ & $\begin{array}{c}\text { Correlation coefficient, } \\
\text { Significance }\end{array}$ \\
\hline \multirow{2}{*}{$\begin{array}{l}\text { Interocclusal } \\
\text { record }\end{array}$} & Left & $34.25^{\circ}$ & \multirow{2}{*}{0.50} & \multirow{2}{*}{$0.15, \mathrm{NS}$} & \multirow{2}{*}{$0.9, \mathrm{HS}$} \\
\hline & Right & $33.75^{\circ}$ & & & \\
\hline \multirow{2}{*}{$\begin{array}{l}\text { Panoramic } \\
\text { radiograph }\end{array}$} & Left & $34.05^{\circ}$ & \multirow{2}{*}{1.75} & \multirow{2}{*}{$0.04, \mathrm{~S}$} & \multirow{2}{*}{$0.65, \mathrm{~S}$} \\
\hline & Right & $35.80^{\circ}$ & & & \\
\hline
\end{tabular}

Table 4: showing the mean difference and correlation coefficient comparing both left and right sides of interocclusal record group and panoramic radiograph group among dentulous subjects using Wilcoxon signed rank test and Karl Pearson's coefficient of correlation test.

\begin{tabular}{|c|c|c|c|c|c|}
\hline Edentulous subjects & Sides & Mean & $\begin{array}{c}\text { Mean } \\
\text { difference }\end{array}$ & $\begin{array}{c}\text { P value, } \\
\text { Significance }\end{array}$ & $\begin{array}{c}\text { Correlation coefficient, } \\
\text { Significance }\end{array}$ \\
\hline \multirow{2}{*}{ Interocclusal record } & Left & $26.75^{\circ}$ & 0.25 & $0.65, \mathrm{NS}$ & $0.85, \mathrm{HS}$ \\
\cline { 2 - 3 } & Right & $26.50^{\circ}$ & $0.25, \mathrm{NS}$ & $0.65, \mathrm{~S}$ \\
\hline \multirow{2}{*}{$\begin{array}{c}\text { Panoramic } \\
\text { radiograph }\end{array}$} & Left & $29.50^{\circ}$ & 0.85 & 0.29 & $0.35^{\circ}$ \\
\cline { 2 - 5 }
\end{tabular}

showed that, the mean difference of condylar guidance values for edentulous patients between left and right sides was 0.25 for interocclusal record group which was statistically non significant (0.65). Table 4 also showed significant correlation for both left and right sides in interocclusal record group $(\mathrm{p}=0.85)$ and panoramic radiographic group $(\mathrm{p}=0.65)$.

\section{DISCUSSION}

The condylar path is a controlling factor and is peculiar to each individual patient. One of the important factor which greatly influences the mandibular movements is the path of the condyle along the articular eminence. ${ }^{3}$ In completely edentulous patients, condylar paths are determined by various factors: ${ }^{4}$ During protrusive movement, as the mandible moves forward there is an influence of the anterior guidance which affects the exact path of the condyle. ${ }^{5}$ As the path of the condyle is constant and cannot be altered by the dentist, ideal dentulous subjects with the minimum overjet and overbite of $2 \mathrm{~mm}$ were selected for the study. Another factor to consider is the precision with which the path of the condyle can be recorded. ${ }^{6,7}$ It has been suggested that the path of the condyle in living subjects depends on a number of factors like presence of soft tissues, articular disc and fibrocartilaginous tissues within the joint space and hence the precise recording the condylar path is difficult. Various authors ${ }^{8}$ have suggested that, the condyle path during protrusion does not follow a path, delineated by the tangent to the exact anatomical configuration of the eminence. On the other hand, interocclusal records are used to adjust the condylar guidance of the articulator. ${ }^{5}$ A protrusive interocclusal record can register the influence of the condylar path over the movements of the mandible. The plane of reference is a relevant parameter to consider, because condylar inclination values cannot be compared when obtained with different planes of reference. ${ }^{9}$

The purpose of this study was to compare the condylar guidance values obtained by interocclusal protrusive records with those obtained by tracing of panoramic radiographic images of dentulous and edentulous subjects. Results of the study showed that the condylar guidance values obtained from the inter-occlusal records were less when compared to the values obtained from tracing the panoramic radiographs. There was no statistically significant difference between the two methods used to record the condylar guidance. In other words, the condylar guidance values remain same irrespective of the technique used. In a study conducted by authors ${ }^{10}$, the relation of the condylar path and the articular eminence was evaluated in 9 patients with ideal occlusion. The discrepancy observed between casts and tracings were less than $0.5 \mathrm{~mm}$ and for patients, it was between 1-2.5 $\mathrm{mm}$. Hence, it was suggested that the condylar and eminence vertical positions vary among patients. The coefficient expressing the slope of the curve $(r=0.82)$ and the rate of change of slope $(r=0.85)$ displayed high levels of significance. It was concluded that in protrusion the condylar head follows closely the anatomical form of the articular eminence. Results also showed a significant correlation between the 
interocclusal record method and the radiographic method for both dentulous and edentulous subjects. Christensen LV et $\mathrm{al}^{11}$ have shown that radiographically determined condylar angles gave higher values than that determined by intraoral recording methods. It seems that the rigid mechanical laws governing the movements of an adjustable articulator seem inapplicable to the dynamic mandibular locomotor system of man. In the literature, however, there is little evidence that the reliability and validity of the procedure have ever been seriously questioned or established.

Since it has been suggested that panoramic radiographs are unique in accurate interpretation of the angular structures and also it results in an excellent projection of a variety of structures on a single film which no other image system can achieve, there are certain limitations in the study pertaining to the panoramic radiography which were as follows:

1. Structures were flattened out which becomes more apparent when the subject is improperly positioned.

2. Ghost images were formed which appeared more blurred than the real images.

3. A panoramic radiograph gives a two dimensional representation of the glenoid fossa and the articular eminence, so the curvature seen on the radiograph may not give the exact inclination of the condylar guidance value.

Although significant correlation between the two methods showed that panoramic radiographic method can be used to set the condylar guidance values on an adjustable articulator, further study relating to interocclusal registrations, radiographic tracings and intersubject variability is required.

\section{CONCLUSION}

It seems that there is no single and well defined method to determine sagittal condylar guidance which is most accurate and reliable. Within the limitations of the study, it can be concluded that
1. Measurement of condylar inclination angles using panoramic radiographs gave higher values, as compared to the interocclusal record method.

2. Panoramic radiographic method revealed less difference between the condylar guidance values obtained for left and right sides as compared to the articulator method.

3. The overall results of this study indicate that the panoramic radiographic images of the outlines of the articular eminence and the glenoid fossa appear to bear a sufficient resemblance to the morphology of the tested structure and can be considered clinically meaningful.

\section{REFERENCES}

1. Zamacona JM, Otaduy E, Aranda E. Study of the sagittal condylar path in edentulous patients. J Prosthet Dent 1992; 68:314-7.

2. Gilboa I, Cardash HS, Israel K, Martin DG. Condylar Guidance: Correlation between articular morphology and Panoramic Radiographic images in Dry human skulls. J Prosthet Dent 2008; 99:477-82.

3. Zarb GA, Bolender CL. Prosthodontic treatment for edentulous patients. 12th edition. India: Elsevier; 2004:245.

4. Heartwell CM, Rahn AO. Syllabus of complete dentures. 4th edition. India: Varghese; 1992: 227.

5. Shillingburg HT, Hobo S, Whitsett LD, Jacobi R, Brackett SE. Fundamentals of fixed prosthodontics.3rd edition. Quintessence; 1997:22.

6. Craddok FW. The accuracy and Practical value of records of the condylar path inclination. J Am Dent Assoc 1949; 38:697709.

7. Winkler S. Essentials of complete denture prosthodontics. 2nd edition. India: A.I.T.B.S; 2000:196.

8. Bell D E, Harris E F. Disclusion in mandibular protrusion. Angle Orthod 1983; 53(2):146-56.

9. Jose DS, Stanley N, Thomas N. Comparison of Condylar Guidance setting obtained from a wax record versus an extra oral tracing: A pilot study. J Prosthet Dent 2003;89:54-9.

10. Corbett N E, DeVincenzo J P, Huffer R A, Shryock E F. The relation of the condylar path to the Articular Eminence in mandibular protrusion. Angle Orthod 1971; 41(4):286-92.

11. Christensen LV, Slabbert JCG. The concept of sagittal condylar guidance: biological fact or fallacy. J Oral Rehab $1978 ; 5: 1-7$. 